\title{
PENGARUH BAHAN TAMBAH FLY ASH BATU BARA TERHADAP KUAT TEKAN BETON MUTU TINGGI
}

\author{
Andi Yusra $^{1}$, T. Budi Aulia ${ }^{2}$, Juf riadi ${ }^{3}$ \\ 1,3) Jurusan Sipil, Fakultas Teknik, Universitas Teuku Umar, Alue Penyareng, Meulaboh Aceh \\ Barat 23615, email: yusra.andi@yahoo.com, ${ }^{2}$ Jurusan Sipil, Fakultas Teknik, Universitas Syiah \\ Kuala
}

\begin{abstract}
Abstrak
Perkembangan daerah Barat Selatan Provinsi Aceh semakin baik, karena pada saat ini telah berdiri pembangkit listrik tenaga uap (PLTU $2 \times 110 \mathrm{~W}$ ) dengan menggunakan bahan bakar batu bara yang menghasilkan limbah hasil pembakaran tanur yaitu abu terbang batu bara (fly ash) dimana pemanfaatan limbah tersebut masih perlu dikembangkan terus menerus. Salah satunya adalah sebagai bahan tambah (additive) pengganti silica fume untuk menghasilkan beton mutu tinggi. Dalam penelitian ini digunakan zat tambah yaitu abu terbang batu bara, dimana jumlah yang ditambahkan adalah $0 \%, 5 \%, 8 \%, 10 \%$ dan $15 \%$ terhadap berat semen, juga digunakan superplastizer (Viscocrete $N 10$ ) sebanyak 1,5\% dari berat semen. Beton direncanakan dengan faktor air semen (FAS) sebesar 0,3. Pengujian dilakukan terhadap kuat tekan beton pada umur 28 dan 56 hari. Pengujian kuat tekan dilakukan pada benda uji silinder beton dengan diameter $15 \mathrm{~cm}$ dan tinggi 30 cm. Jumlah benda uji 30 buah, setiap variabel menggunakan 3 buah benda uji. Hasil pengujian kuat beton pada umur 28 hari menunjukkan pada penambahan masing-masing fly ash, 0\% menghasilkan kuat tekan (56,21 MPa), 5\% (56,21 MPa), 8\% (51,68 MPa), 10\% (56,59 MPa), dan 15\% (60,36 $\mathrm{MPa}$ ). Untuk umur pengujian 56 hari, 0\% menghasilkan kuat tekan (64,13 MPa), 5\% (63,26 MPa), $8 \%(56,59 \mathrm{MPa}), 10 \%(63,94 \mathrm{MPa})$, dan $15 \%$ (66,96 MPa). Terjadi penambahan kekuatan 10,94\% pada umur 56 hari dibandingkan kuat tekan pada umur 28 hari dengan penambahan fly ash batu bara sebesar $15 \%$
\end{abstract}

Kata kunci : Kuat Tekan, Fly Ash batu bara, dan Umur Pengujian.

\begin{abstract}
Growth of regional south-west of Aceh province is good progressively, because at the moment have stood the power station steam power ( PLTU $2 \times 110 \mathrm{~W}$ ) by using fuel petrify the embers yielding waste of result of kiln combustion that is flown by dusty of stone smolder the fly ash where the waste exploiting still require to be developed continuously. One of them is upon which add the additive of substitution of silica fume to yield the high strength concrete. In this research used additives that is fly ash with the addition of percentage of the weight of the cement $0 \%, 5 \%, 8 \%, 10 \%$ and $15 \%$, it also used superplasticizer (viscocrete $N$-10) with the addition of percentage of the weight of the cement 1,5\% Concrete was designed with water cement ratio 0,30. Test were conducted was strength test of high strength concrete at 28 and 56 age days. Compressive strength test covered of concrete cylinder by $15 \mathrm{~cm}$ in diameter and $30 \mathrm{~cm}$ height. Amount of sample test was 30, where each variable used 3 samples. Result of high strength concrete compression test at age 28 days, show at addition of each fly ash, 0\% yielding strength (56,21 MPA), 5\% (56,21 MPA), 8\% 51,68 MPA), 10\% (56,59 $M P A)$, and $15 \%(60,36 \mathrm{MPA})$. For the high strength concrete compression test at age 56 days, $0 \%$ yielding strength (64,13 MPA), 5\% (63,26 MPA), 8\% (56,59 MPA), 10\% (63,94MPa), and 15\% (66,96 MPA). Happen by strength addition 10,94\% at age 56 day compared to strength at age 28 days with the addition of fly ash equal to $15 \%$
\end{abstract}

Keywords : Strength, Fly Ash, and Age of Test 


\section{PENDAHULUAN}

Pertumbuhan daerah Barat Selatan Provinsi Aceh semakin membaik pasca terjadinya bencana tsunami, salah satu penyebabnya adalah pada saat ini telah berdiri pembangkit listrik tenaga uap (PLTU 2 x $110 \mathrm{~W}$ ) yang sangat menunjang pertumbuhan ekonomi daerah, juga mempercepat pertumbuhan pembangunan-pembangunan infra struktur lainnya. Pengoperasian PLTU tersebut menggunakan bahan bakar batu bara yang menghasilkan limbah hasil pembakaran tanur yaitu abu terbang batu bara (fly ash) dimana pemanfaatan limbah tersebut masih perlu terus dikembangkan dan berdasarkan beberapa referensi abu terbang (fly ash) batu bara dapat digunakan dalam pembuatan beton.

Ilmu teknologi beton yang berkembang kian pesat pada masa sekarang, terutama mengenai pembuatan beton mutu tinggi dengan menggunakan nilai FAS yang kecil, penggunaan bahan tambah (additive) dan admixture yang biaya pembuatannya cukup mahal, sehingga diperlukan penelitianpenelitian yang berkelanjutan agar diperoleh bahan-bahan baru sebagai alternatif pengganti untuk pembuatan beton mutu tinggi dengan menggunakan bahan bahan yang lebih murah serta tetap mempertahankan kualitas dan kekuatan beton itu sendiri.

Tujuan dari penelitian ini adalah untuk mengetahui besarnya pengaruh penggunaan bahan tambah fly ash terhadap kuat tekan beton mutu tinggi. Bahan tambah yang digunakan ada adalah fly ash dengan persentase penambahan $0 \%, 5 \%, 8 \%, 10 \%$ dan 15\% dari berat semen terhadap kuat tekan dengan faktor air semen (FAS) 0,30. Penambahan zat admixture yaitu superplasticizer (Viscocrete N 10) masing-masing $1,5 \%$ terhadap berat semen. Sebelum pembuatan beton dimulai terlebih dahulu dilakukan pemeriksaan sifat-sifat fisis terhadap agregat sebagai material pembentuk beton untuk mendapatkan material yang baik sesuai dengan Anonim (1982). Pengujian kuat tekan dilakukan pada umur 28 hari dan 56 hari. Rancangan campuran beton mutu tinggi ini diperhitungkan untuk kekuatan rencana $70 \mathrm{MPa}$ (Aulia, 1999). Agregat kasar yg digunakan adalah batu pecah dengan diameter agregat maksimum $16 \mathrm{~mm}$. Gradasi butiran yang digunakan dalam perencanaan campuran beton ini adalah (0 - 2) mm, (2 - 5) mm, (5 - 8) mm, (8 - 11) mm dan (11 - 16) mm (Mahdi, 2008).

\section{Beton Mutu Tinggi}

American Concrete Institute (1997) menyatakan bahwa, definisi beton mutu tinggi adalah beton yang memiliki kekuatan lebih besar dari 6000 Psi atau 41,4 MPa. Menurut Dobrowolski (1988), beton mutu tinggi adalah beton dengan kuat tekan lebih besar dari 6000 Psi dan digunakan untuk mengecilkan ukuran kolom dan balok agar lebih menguntungkan pada bentang yang lebih panjang dan dapat meringankan struktur.

\section{Agregat}

Agregat yang digunakan dalam pembuatan beton dapat berupa agregat alam atau agregat buatan (artificial aggregates). Agregat dapat dibedakan berdasarkan ukurannya, yaitu agregat kasar 
dan agregat halus. Batasan antara agregat halus dan agregat kasar yaitu 4,80 mm (British Standard) atau 4,75 mm (Standar ASTM). Agregat kasar adalah batuan yang ukurannya lebih besar dari 4,75 $\mathrm{mm}$ dan agregat halus adalah batuan yang lebih kecil dari $4,75 \mathrm{~mm}$.

\section{Bahan Tambah}

\section{Abu hasil pembakaran batu bara (fly ash)}

Menurut Mulyono (2005 : 125), abu terbang (fly ash) didefinisikan sebagai butiran halus hasil residu pembakaran batu bara atau bubuk batu bara. Fly ash dapat dibedakan menjadi dua, yaitu abu terbang yang normal dihasilkan dari pembakaran batu bara antrasit atau batu bara bitomius dan abu terbang kelas $\mathrm{C}$ yang dihasilkan dari batu bara jenis lignite atau subbitumius. Abu terbang kelas $\mathrm{C}$ kemungkinan mengandung kapur (lime) lebih dari 10\% beratnya. Kandungan kimia yang dibutuhkan dalam fly ash tercantum dalam Tabel 2.2 (Mulyono, 2005 : 126).

Abu terbang merupakan limbah pembakaran batu bara yang butirannya lebih halus dari pada semen portland, yang mempunyai sifat-sifat hidrolis. Pada awalnya abu terbang ini digunakan sebagai bahan penambah semen dengan kadar 5 - 20\% dengan maksud untuk menambah plastisitas adukan beton dan menambah kekedapan beton (Suhud, 1993). Pada beton keras penggunaan abu terbang $10-$ 15\% sebagai bahan pengganti semen dapat menambah kekuatan beton (Surya, 2002; Udin, 1994).

Tabel 1 Kandungan Kimia Fly Ash

\begin{tabular}{|l|l|c|}
\hline \multicolumn{1}{|c|}{ Senyawa Kimia } & Jenis F & Jenis C \\
\hline $\begin{array}{l}\text { Oksida Silika }\left(\mathrm{SiO}_{2}\right)+\text { Oksida Alumina }\left(\mathrm{AL}_{2} \mathrm{O}_{3}\right)+\text { Oksida Besi } \\
\left(\mathrm{Fe}_{2} \mathrm{O}_{3}\right) \text {, minimum \% }\end{array}$ & 70.0 & 50.0 \\
\hline Trioksida Sulfur $\left(\mathrm{SO}_{3}\right)$, maksimum \% & 5.0 & 5.0 \\
\hline Kadar Air, Maksimum \% & 3.0 & 3.0 \\
\hline Kehilangan Panas, maksimum \% & $6.0^{\mathrm{A}}$ & 6.0 \\
\hline
\end{tabular}

${ }^{\mathrm{A}}$ Penggunaan sampai dengan $12 \%$ masih diizinkan jika ada perbaikan kinerja atau hasil test laboratorium menunjukkan demikian.

Sumber : Mulyono, 2005

\section{METODE PENELITIAN}

\section{Material}

Material yang digunakan dalam penelitian ini adalah semen portland, agregat dari Krueng Aceh, bahan tambahan fly ash batu bara dari PLTU Nagan Raya dan superplasticizer produksi PT. Sika Indonesia. Semen yang digunakan adalah semen portland Tipe I produksi PT. Semen Andalas Indonesia (PT. SAI). Pemeriksaan laboratorium terhadap semen ini tidak dilakukan karena telah memenuhi Standar Nasional Indonesia (SNI) 15-20490-1994. Pemeriksaan hanya dilakukan secara visual terhadap kantong yang tidak robek dan keadaan butiran (tidak terdapat bongkahan-bongkahan yang keras) pada semen tersebut. 
Pemeriksaan terhadap agregat kasar dan agregat halus dilakukan terhadap sifat-sifat agregat yang meliputi berat jenis (specific gravity), penyerapan (absorbtion), berat volume (bulk density), analisa saringan (sieve analyisis), sifat-sifat ketahanan agregat dan kadar bahan organik. Pemeriksaan sifat-sifat fisis agregat kasar dan agregat halus didasarkan pada standar ASTM. Agregat kasar yang digunakan adalah batu pecah dengan diameter agregat maksimum $16 \mathrm{~mm}$.

Bahan tambahan fly ash batu bara didapat dari hasil pembakaran tanur tinggi PLTU Nagan Raya, sedangkan superplasticizer diperoleh dari PT. Sika Indonesia. Pemeriksaan komposisi kimia terhadap fly ash batu bara, adalah kandungan Silicon Dioxide $\left(\mathrm{SiO}_{2}\right)$, Aluminium Oxide $\left(\mathrm{Al}_{2} \mathrm{O}_{2}\right)$, Ferric Oxide $\left(\mathrm{Fe}_{2} \mathrm{O}_{3}\right)$ dan Sulphur Oxide $\left(\mathrm{SO}_{3}\right)$. Pemeriksaan kandungan kimia ini dilakukan di laboratorium penguji BARISTAND Industri Banda Aceh.

Superplasticizer yang digunakan pada penelitian ini adalah Sika Viscocrete N-10, data teknis Sika Viscocrete-10 dapat dilihat pada Tabel 3.1 berikut ini.

Tabel 2 Data Teknis Sika Viscocrete-10

\begin{tabular}{|l|l|}
\hline Dosis & $0,5 \%-1,8 \%$ dari berat semen \\
\hline Berat Jenis & $1,06 \mathrm{~kg} / \mathrm{l}$ \\
\hline Umur Pemakaian & 12 bulan \\
\hline Penyimpanan & Di tempat yang teduh, kering \\
\hline Kemasan & $200 \mathrm{~kg}$ \\
\hline
\end{tabular}

Sumber : PT. Sika Indonesia

\section{Perencanaan dan Pengerjaan Campuran Beton}

Perencanaan komposisi campuran beton (concrete mix design) direncanakan berdasarkan metode perbandingan berat material pembentuk beton. Untuk rancangan campuran beton mutu tinggi ini diperkirakan kuat tekan rencana 70 Mpa untuk benda uji silinder $15 / 30 \mathrm{~cm}$, faktor air semen 0,30, persentase fly ash yang digunakan $0 \%, 5 \%, 8 \%, 10 \%$ dan $15 \%$ dari berat semen.

\section{Rancangan Benda Uji}

Untuk maksud penelitian ini dibuat benda uji yang berjumlah 30 buah dengan bentuk silinder (Ø $15 \mathrm{~cm}, \mathrm{~T}=30 \mathrm{~cm}$ ), dengan masing-masing variabel berjumlah 3 buah benda uji.

\section{Pengujian Kuat Tekan Beton}

Pengujian kuat tekan silinder beton dilakukan pada umur 28 hari dan 56 hari. Pengujian dilakukan dengan menggunakan mesin penguji kuat tekan merek Ton Industrie kapasitas 100 ton dan 400 ton yang berada di Laboratorium Bahan dan Konstruksi Fakultas Teknik UNSYIAH. 


\section{HASIL DAN PEMBAHASAN}

\section{Sifat-Sifat Fisis Agregat}

Data pendukung penelitian diperoleh dari hasil pemeriksaan sifat-sifat fisis agregat. Hasil pemeriksaan menunjukkan bahwa agregat yang digunakan memenuhi syarat sebagai material pembentuk beton.

\section{Berat volume}

Hasil perhitungan berat volume rata-rata yang diperoleh untuk setiap jenis agregat diperlihatkan pada Tabel 3 berikut ini.

\begin{tabular}{|c|c|c|c|c|}
\hline \multirow[b]{2}{*}{ No } & \multirow{2}{*}{$\begin{array}{c}\text { Jenis } \\
\text { Agregat }\end{array}$} & \multirow[b]{2}{*}{ Berat Volume $(\mathrm{kg} / \mathrm{l})$} & \multicolumn{2}{|c|}{ Referensi } \\
\hline & & & Orchard (1979) & Troxell (1968) \\
\hline 1. & Coarse Aggregate (11-16 mm) & 1,566 & \multirow{5}{*}{$>1,445$} & \multirow{3}{*}{$>1,560$} \\
\hline 2. & Coarse Aggregate $(8-11 \mathrm{~mm})$ & 1,553 & & \\
\hline 3. & Coarse Aggregate $(5-8 \mathrm{~mm})$ & 1,546 & & \\
\hline 4. & Coarse Sand (2-5 mm) & 1.469 & & \multirow{2}{*}{$>1,400$} \\
\hline 5. & Fine Sand $(0-2 \mathrm{~mm})$ & 1,465 & & \\
\hline
\end{tabular}

Agregat yang digunakan dalam penelitian ini dapat digunakan sebagai material pembentuk beton sebagaimana yang disarankan oleh Orchard (1979) yaitu berat volume agregat yang baik lebih besar dari 1,445 kg/l dan Troxell (1968) yaitu berat volume agregat kasar lebih besar dari 1,560 kg/l dan untuk pasir kasar serta pasir halus lebih besar dari 1,400 kg/l.

\section{Berat jenis dan absorbsi}

Hasil perhitungan berat jenis dan absorbsi zat tambahan diperlihatkan pada Tabel $4-5$ berikut ini.

Tabel 4 Hasil pemeriksaan perhitungan berat jenis agregat

\begin{tabular}{|c|c|c|c|c|}
\hline \multirow{2}{*}{ No } & \multirow{2}{*}{ Jenis Agregat } & \multicolumn{2}{|c|}{ Berat Jenis } & \multirow{2}{*}{$\begin{array}{c}\text { Referensi } \\
\text { Troxell (1968) }\end{array}$} \\
\hline & & $\mathrm{SG} \quad(\mathrm{SSD})$ & $\mathrm{SG}$ (OD) & \\
\hline 1. & Coarse Aggregate (11-16mm) & 2,734 & 2,69 & \multirow{3}{*}{$2,500-2,800$} \\
\hline 2. & Coarse Aggregate $(8-11 \mathrm{~mm})$ & 2,685 & 2,64 & \\
\hline 3. & Coarse Aggregate $(5-8 \mathrm{~mm})$ & 2,517 & 2,489 & \\
\hline 4. & Coarse Sand (2-5 mm) & 2,432 & 2,398 & \multirow{2}{*}{$2,000-2,600$} \\
\hline 5. & Fine Sand (0-2 mm) & 2,513 & 2,475 & \\
\hline
\end{tabular}


Tabel 5 Hasil pemeriksaan perhitungan absorbsi agregat

\begin{tabular}{|c|l|c|c|}
\hline No & \multicolumn{1}{|c|}{ Jenis Agregat } & Absorbsi $(\%)$ & Referensi \\
& & & Orchard (1979) \\
\hline 1. & Coarse Aggregate $(11-16 \mathrm{~mm})$ & 1,657 & \multirow{2}{*}{$0,400-1,900$} \\
\hline 2. & Coarse Aggregate $(8-11 \mathrm{~mm})$ & 1,708 & \\
\hline 3. & Coarse Aggregate $(5-8 \mathrm{~mm})$ & 1,12 & \\
\hline 4. & Coarse Sand $(2-5 \mathrm{~mm})$ & 1,413 & \\
\hline 5. & Fine Sand $(0-2 \mathrm{~mm})$ & 1,519 & \\
\hline
\end{tabular}

Tabel 6 Hasil pemeriksaan perhitungan berat jenis dan absorbsi zat tambahan

\begin{tabular}{|c|c|c|c|c|c|}
\hline \multirow{2}{*}{ No } & Zat Tambahan & \multicolumn{2}{|c|}{ Berat Jenis } & Absorbsi (\%) & $\begin{array}{c}\text { Referensi SG } \\
\text { ACI Committee 226 }\end{array}$ \\
\cline { 1 - 2 } & Fly ash batu bara & SG (SSD) & SG (OD) & $2,150-2,600$ \\
\hline
\end{tabular}

Berdasarkan Tabel 4 terlihat bahwa berat jenis agregat jenuh air kering permukaan (SSD) yang digunakan telah memenuhi ketentuan yang disarankan oleh Troxell (1968) yaitu untuk kerikil berkisar antara 2,5 - 2,8 dan untuk pasir berkisar antara 2,0 - 2,6. Sedangkan berat jenis agregat kering oven (OD) yang diperoleh masih masuk dalam kategori yang ditentukan oleh Troxell (1968) yaitu yaitu untuk kerikil berkisar antara 2,5 - 2,8 dan untuk pasir berkisar antara 2,0 - 2,6. Selanjutnya pada Tabel 5 dapat dilihat bahwa nilai absorbsi kerikil, pasir kasar, dan pasir halus yang diperoleh masih sesuai dengan nilai absorbsi yang ditentukan oleh Orchard (1979) yaitu 0.4\% sampai dengan 1.9\%. Pada tabel 6 diperlihatkan hasil berat jenis dan absorbsi dari bahan tambah yaitu fly ash batu bara. Berat jenis bahan tambah yang digunakan lebih kecil dari yang ditentukan oleh ACI Committee 226.

\section{Susunan Butiran Agregat (gradasi)}

Data yang diperoleh dari analisa saringan digunakan untuk melihat susunan butiran agregat yang digunakan dalam campuran beton. Nilai fineness modulus yang diperoleh dari analisa saringan dapat dilihat pada Tabel 4.5. Fineness modulus tersebut telah memenuhi ketentuan ASTM (Anonim, 2004) yaitu diantara 5.5 - 8.0 untuk kerikil, diantara 2.9 - 3.2 untuk pasir kasar dan diantara $2.2-2.6$ untuk pasir halus.

Tabel 7 Nilai Fineness Modulus (FM) Agregat.

\begin{tabular}{|c|c|c|c|c|}
\hline \multirow{2}{*}{ No } & \multirow{2}{*}{$\begin{array}{c}\text { Jenis } \\
\text { Agregat }\end{array}$} & \multirow{2}{*}{ Modulus Kehalusan (FM) } & \multicolumn{2}{|c|}{ Referensi } \\
\hline & & & (2004 sampai dengan) & Mulyono $\quad(2005)$ \\
\hline 1. & Coarse Aggregate (11-16mm) & 8 & \multirow{4}{*}{$5,500-8,000$} & \multirow{4}{*}{$5,000-8,000$} \\
\hline 2. & Coarse Aggregate $(8-11 \mathrm{~mm})$ & 7 & & \\
\hline 3. & Coarse Aggregate $(5-8 \mathrm{~mm})$ & 6 & & \\
\hline 4. & Coarse Aggregate $(2-5 \mathrm{~mm})$ & 5 & & \\
\hline 5 . & Fine Sand $(0-2 \mathrm{~mm})$ & 2,586 & $2,200-2,600$ & $1,500-3,800$ \\
\hline 6. & Agregat campuran & 5,626 & $4,000-7,000$ & $5,000-6,000$ \\
\hline
\end{tabular}

Hasil perhitungan fineness modulus agregat campuran adalah 5,626. Nilai ini telah sesuai 
dengan ketentuan diperlihatkan standar ASTM (Anonim, 2004) yaitu antara 4,0 - 7,0. Hasil perhitungan dapat dilihat bahwa susunan butiran agregat campuran berada pada daerah "3" (Anonim, 1971) yang berarti susunan butiran agregat yang digunakan adalah baik (Gambar 1). Berdasarkan Mulyono (2005), susunan butiran agregat campuran juga masuk dalam kategori gradasi baik (Gambar 2) berikut ini.

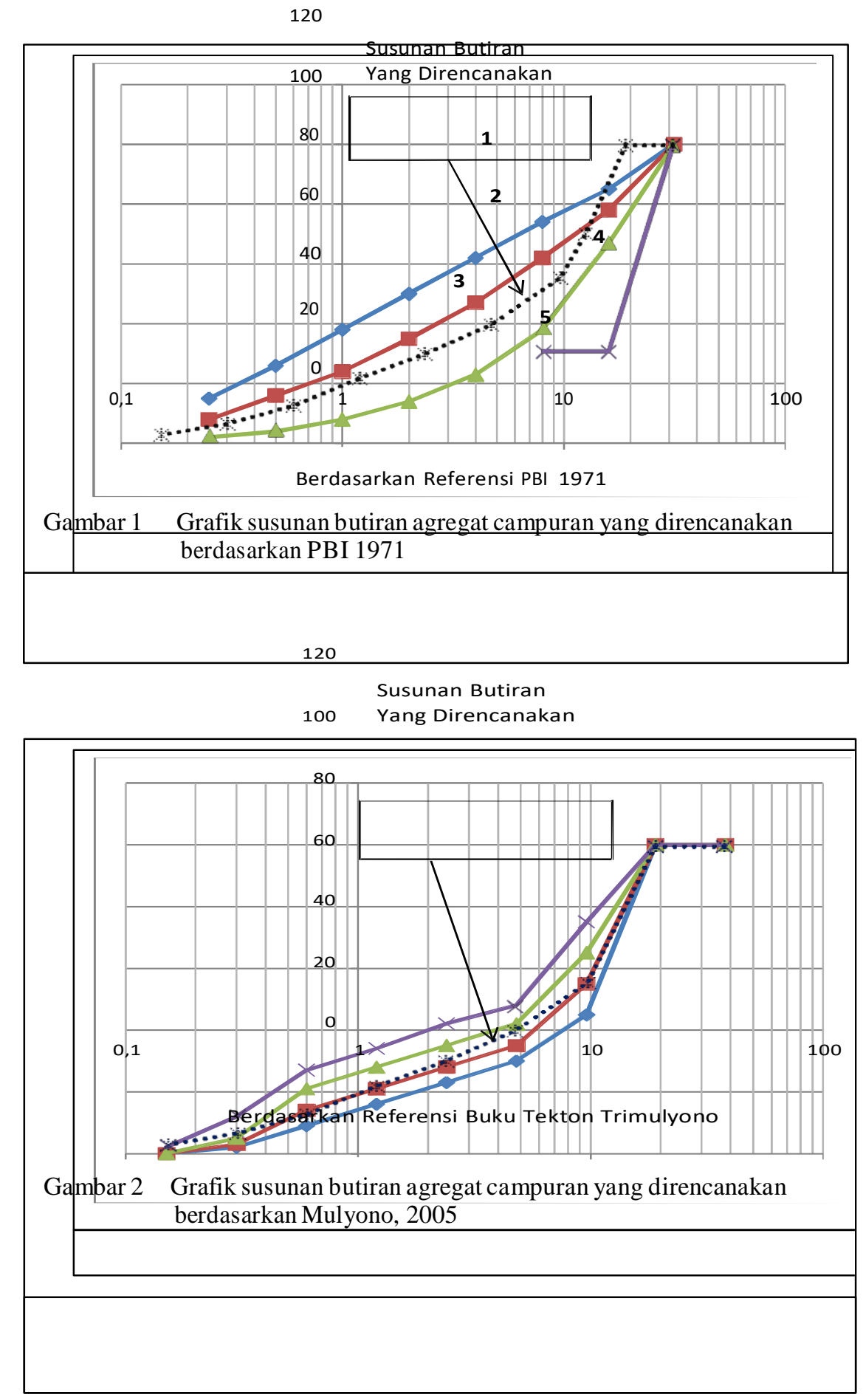




\section{Kandungan bahan organik.}

Hasil pemeriksaan kandungan bahan organik pada agregat halus menunjukkan bahwa warna larutan yang timbul adalah kuning muda. Hal ini menandakan bahwa pasir yang digunakan untuk campuran beton termasuk dalam kategori tidak mengandung bahan organik berlebihan dan dapat digunakan untuk campuran beton.

\section{Pemeriksaan Kandungan Kimia Zat Tambahan.}

Pemeriksaan Kandungan kimia untuk zat tambahan dilakukan di BARISTAND Industri Banda Aceh. Hasil pemeriksaan diperlihatkan pada Tabel 4.6. Dari Tabel 4.6 di atas terlihat bahwa jumlah kandungan $\mathrm{SiO}_{2}, \mathrm{Al}_{2} \mathrm{O}_{3}$, dan $\mathrm{Fe}_{2} \mathrm{O}_{3}$ untuk fly ash batu bara adalah 26,65\%; 9,6\%; 17,56\%; dan 2,51\%. Berdasarkan ketentuan ASTM jenis fly ash batu bara termasuk ke dalam kategori C.

Tabel $8 \quad$ Komposisi material untuk 3 buah benda uji silinder beton $(15 / 30 \mathrm{~cm})$

\begin{tabular}{|c|c|c|c|c|}
\hline Zat Tambahan & Parameter Uji & Satuan & Metode Uji & Hasil \\
\hline \multirow{4}{*}{$\begin{array}{c}\text { Fly ash Batu } \\
\text { Bara }\end{array}$} & $\mathrm{SiO}_{2}$ & $\%$ & Gravimetri & 26,65 \\
\cline { 2 - 5 } & $\mathrm{Al}_{2} \mathrm{O}_{3}$ & $\%$ & Gravimetri & 9,6 \\
\cline { 2 - 5 } & $\mathrm{Fe}_{2} \mathrm{O}_{3}$ & $\%$ & AAS & 17,56 \\
\cline { 2 - 5 } & $\mathrm{SO}_{3}$ & $\%$ & Titrimetri & 2,51 \\
\hline
\end{tabular}

\section{Rancangan Campuran Beton}

Perhitungan rancangan campuran (mix design) beton dengan penambahan fly ash batu bara.

Perhitungan ini berdasarkan perhitungan perbandingan berat material sesuai dengan penelitian (Aulia, 1999) dan (Mahdi, 2008).

Tabel 9 Komposisi material untuk 3 buah benda uji silinder beton $(15 / 30 \mathrm{~cm})$

\begin{tabular}{|l|c|r|r|r|r|}
\hline \multirow{2}{*}{ Material } & \multicolumn{5}{|c|}{ Jumlah Material Yang Digunakan Untuk 3 Benda Uji } \\
& \multicolumn{5}{c|}{ ( Kg ) } \\
\cline { 2 - 6 } & \multicolumn{5}{c|}{ Fly Ash Batu Bara (FABB) } \\
\cline { 2 - 6 } & $0 \%$ & $5 \%$ & $8 \%$ & $10 \%$ & $15 \%$ \\
\hline Semen & 10,497 & 10,497 & 10,497 & 10,497 & 10,497 \\
\hline Fly Ash & 0,000 & 0,525 & 0,840 & 1,050 & 1,575 \\
\hline Pasir 0-2 mm & 9,479 & 8,982 & 8,683 & 8,484 & 7,986 \\
\hline Batu Pecah 2-5 mm & 3,160 & 2,994 & 2,894 & 2,828 & 2,662 \\
\hline Batu Pecah 5-8 mm & 4,740 & 4,491 & 4,342 & 4,242 & 3,993 \\
\hline Batu Pecah 8-11 mm & 4,740 & 4,491 & 4,342 & 4,242 & 3,993 \\
\hline Batu Pecah 11-16 mm & 9,479 & 8,982 & 8,683 & 8,484 & 7,986 \\
\hline Air & 3,149 & 3,149 & 3,149 & 3,149 & 3,149 \\
\hline Super Plasticizer & 0,157 & 0,157 & 0,157 & 0,157 & 0,157 \\
\hline
\end{tabular}

Berdasarkan tabel 9 dapat dilihat komposisi dari masing-masing bahan pembentuk beton dalam satuan berat dimana jumlah berat semen tetap dipertahankan sedangkan jumlah bahan tambah masingmasing sesuai dengan persentase penambahan. Komposisi tersebut untuk jumlah benda uji silinder sebanyak 3 buah dengan ukuran masing-masing benda uji adalah berdiameter $15 \mathrm{~cm}$ dan tinggi $30 \mathrm{~cm}$. 


\section{Kuat tekan silinder beton}

Pengujian kuat tekan beton dilakukan pada saat benda uji berumur 28 hari dan 56 hari. Benda uji yang diuji terlebih dahulu ditimbang beratnya.

Tabel 10 Hasil pengujian kuat tekan untuk benda uji beton dengan penambahan fly ash $(\varnothing 15 \mathrm{~cm} \&$ $\mathrm{T} 30 \mathrm{~cm})$

\begin{tabular}{|c|c|c|c|c|c|c|}
\hline \multirow{2}{*}{ Umur (hari) } & \multirow{2}{*}{ Fly Ash } & \multicolumn{5}{|c|}{ Kuat Tekan Beton (MPa) } \\
\hline & & FA $0 \%$ & FA $5 \%$ & FA $8 \%$ & FA $10 \%$ & FA $15 \%$ \\
\hline \multirow{3}{*}{28} & \multirow{3}{*}{ Batu Bara } & 54,325 & 56,588 & 49,798 & 54,325 & 56,588 \\
\hline & & 55,457 & 56,588 & 50,930 & 58,852 & 62,247 \\
\hline & & 58,852 & 55,457 & 54,325 & 56,588 & 62,247 \\
\hline \multicolumn{2}{|c|}{ Rata-rata } & 56,211 & 56,211 & 51,684 & 56,588 & 60,361 \\
\hline \multirow{3}{*}{56} & \multirow{3}{*}{ Batu Bara } & 70,736 & 62,247 & 57,720 & 56,023 & 67,906 \\
\hline & & 62,247 & 70,170 & 56,588 & 70,736 & 67,906 \\
\hline & & 59,418 & 58,852 & 55,457 & 65,077 & 65,077 \\
\hline & & 64,134 & 63,756 & 56,588 & 63,945 & 66,963 \\
\hline
\end{tabular}

Berdasarkan hasil pengujian kuat tekan beton mutu tinggi, diperoleh bahwa kuat tekan beton mutu tinggi menunjukkan bahwa mutu beton termasuk beton mutu tinggi sesuai dengan referensi yang tercantum dalam tinjauan pustaka. Kekuatan yang paling tinggi didapat pada penambahan bahan tambah fly ash 15\% dengan umur pengujian 56 hari yaitu sebesar 66,96 MPa lebih besar dari 41,4 MPa (ACI, 2004).

\section{PENUTUP}

\section{KESIMPULAN}

1. Hasil pengujian kuat tekan terbesar diperoleh dari beton dengan penambahan fly ash sebesar $15 \%$ dengan kuat tekan rata-rata 66,96 MPa pada pengujian umur 56 hari.

2. Penggunaan bahan tambah fly ash meningkatkan kuat tekan beton pada umur pengujian 56 hari, hal ini menunjukkan bahwa bahan tambah tersebut bisa dipakai sebagai pengganti Silica Fume, sebagai bahan pengganti alternatif dalam pembuatan beton mutu tinggi.

3. Terjadi peningkatan kuat tekan sebesar $10,94 \%$ pada beton umur 56 hari dengan persentase penambahan fly ash $15 \%$ dari berat semen.

4. Beton yang dihasilkan termasuk kedalam kategori beton mutu tinggi.

\section{DAFTAR PUSTAKA}

ACI Committee 234, 1995, Guide for The Use of Silica Fume in Concrete, Vol. 92, No. 4, ACI Materials Journal.

Anonim, 1971, Peraturan Beton Bertulang Indonesia 1971 (NI-2), Direktorat Penyelidikan Masalah Bangunan Direktorat Jenderal Cipta Karya Departemen Pekerjaan Umum dan Tenaga 
Listrik, Bandung.

Anonim, 1991, Recommended Practice for Selecting Proportion for Normal and Heavy Weight Concrete, American Institute Committee 211, ACI Standard

Aulia, T. B., 1999, Effect of Mechanical Properties of Aggregate on The Ductility of High Performance Concrete, Karsten Deutschman, Lacer No. 4, 133 - 147.

Dobrowolski, A. J., 1988, Concrete Construction Hand Book New York, The McGraw-Hill Companies, Inc.

Mahdi, 2008, Pengaruh Agregat Terhadap Sifat-Sifat Mekanis Beton Mutu Tinggi, Tesis, Teknik Sipil, Universitas Syiah Kuala.

Mehta, P.K. dan Monteiro, P.J.M., 2006, Concrete, Mac-Graw Hill, USA, pp. 121-198

Muttaqin, 1998, Perilaku Mekanik Beton Dengan Agregat Ringan Buatan Bergradasi Tidak Kontinu, Tesis, Teknik Sipil, Institut Teknologi Bandung. 